\title{
Left Parasternal Impulse in Pulmonary Stenosis and Atrial Septal Defect
}

\author{
R. E. NAGLE* AND F. A. TAMARA \\ From Sheffield Cardio-Thoracic Unit, City General Hospital, Sheffield 5
}

In health, the cardiac impulse at the left sternal border consists of outward movement which is brief and of small amplitude and is followed by inward retraction (Gillam, Deliyannis, and Mounsey, 1964).

In the diagnosis of congenital heart disease a distinction is often made between the impulse found in atrial septal defect, of great amplitude but brief duration, and that in pulmonary stenosis characterized by outward movement which is abnormally prolonged throughout systole (Gillam et al., 1964; Benchimol, Wu, and Dimond, 1966; Wood, 1956). Clinical observation led us to suspect that the difference between these two kinds of impulse was sometimes less definite, and the diagnostic interpretation less reliable, than the earlier reports seemed to imply. We therefore used an impulse recorder to make objective records of the left parasternal impulse in pulmonary stenosis and atrial septal defect to obtain a direct comparison in a larger number of patients than has been reported up to now.

Since the duration of the impulse was likely to be its most important distinguishing feature, it was obviously essential to use a recorder capable of recording prolonged movements accurately. Two different impulse recorders were available for use in this study, and we took the opportunity of making a double comparison, not only between patients with different diseases, but also between the records given by different impulse recorders on the same patient. In this way we hoped to assess the clinical significance of abnormalities of the cardiac impulse at the left sternal border and also to determine how these movements should be recorded.

\section{SubJects AND Methods}

Studies were made on 30 patients with pulmonary stenosis and 28 with atrial septal defect when they were

Received September 12, 1966. 15.

^ Present address: Queen Elizabeth Hospital, Birmingham admitted to hospital for diagnostic investigation. The diagnosis was made on clinical, radiological, and electrocardiographic criteria, and was confirmed in every case by cardiac catheterization and angiocardiography. Many of the patients were children, the youngest being 4 years old, and the oldest adult was 39 .

The electrocardiographic criteria used for the diagnosis of right ventricular hypertrophy were those of Goodwin and Abdin (1959). The only radiological evidence accepted as reliably indicating right ventricular hypertrophy was an appearance of excessive trabeculation and increase in thickness of the wall observed on right ventricular angiocardiography. Such radiological abnormalities imply the presence of severe hypertrophy.

Cardiac catheterization was performed under local anæsthesia with omnopon as premedication for adults and chloral hydrate for children. Intravascular pressures were measured with strain-gauge transducers and right ventricular angiograms were taken using Angio Conray 420 as the contrast medium with full-size pictures taken in two planes by an Elema changer.

The two impulse recorders employed are to be described in greater detail in a future publication and we shall describe here only the salient features as they affected their performance in this trial. Both instruments were mounted on the patient's bed rather than on his chest, and recorded movement of a small area of the chest wall by means of a probe projecting from the transducer. Movement of the impulse was therefore related to a fixed external point rather than to the surrounding tissues.

The first recorder was a modified condenser microphone with a probe attached to its diaphragm ${ }^{\star}$. Such a transducer records brief movements faithfully but responds to a sudden maintained displacement by a signal that initially deflects and then gradually declines to its original baseline (Fig. 1). The time taken for the signal to fall to the fraction $1 / \mathrm{e}(0.37)$ of its initial value is known as the time constant of the system, and the longer this is, the more prolonged the displacement it will record without distortion. In general, the time constant should be several times as long as the duration of the longest wave of motion to be recorded. Because 

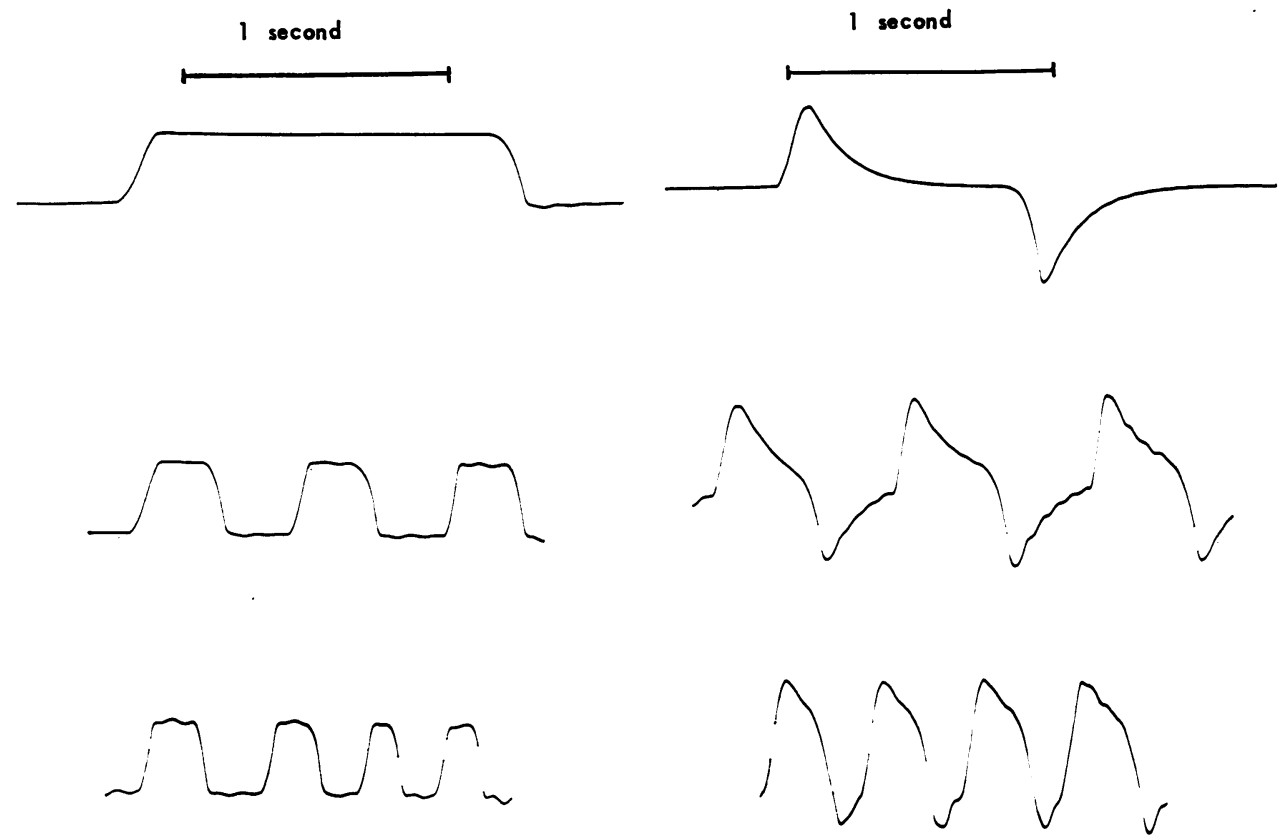

D.C.

A.C.

FIG. 1.-Response of the D.C. and A.C. transducers to square wave motion.

such a transducer can only respond to phasic motion we shall refer to it as an alternating current (A.C.) transducer. It may be used with a D.C. amplifier or with an A.C. amplifier, provided the time constant of the amplifier is at least as long as that of the transducer.

The time constant of the A.C. system used in these studies was $0 \cdot 15 \mathrm{sec}$. The time constant of a transducer is influenced by the input impedance of the amplifier used with it, and that of the A.C. recorder would be longer if it were used with the amplifier for which it was designed.

The other impulse recorder was a modification of that described by Beilin and Mounsey (1962). For the photoelectric transducer of their recorder we substituted a differential transformer displacement transducer*. This gives an output signal proportional to the displacement of its probe regardless of the time for which the displacement is maintained. The time constant of this device was therefore infinitely long and we describe it as a direct current (D.C.) transducer. A D.C. amplifier must be used with it.

Similar, approximately square wave, displacement signals were applied to the two impulse recorders to obtain the pairs of tracings shown in Fig. 1 which contrasts the distortion of slow prolonged movement

* Sanborn 7DCDT. produced by the A.C. system with the comparatively faithful reproduction of motion by the D.C. instrument.

In our studies both recorders were used with D.C. amplifiers, and the output was recorded on a photographic recorder together with the electrocardiogram and phonocardiogram to serve as reference tracings. The records were made at the end of quiet expiration with the breath held, and the subjects lay in the supine position with the trunk propped up at 45 degrees. Many children were unable consciously to hold their breath and we then had to make use of spontaneous pauses in respiration.

\section{RESULTS}

Left Parasternal Impulse in Pulmonary Stenosis. Records were obtained from 30 patients with pulmonary stenosis. They were easily divided into three principal groups according to the form and duration of the cardiac impulse as it was recorded by the D.C. transducer (Fig. 2). The first group had impulses indistinguishable from normal, with brief outward movement followed by a return to the presystolic baseline within the first half of systole (Fig. 2A). In two patients the outward movement, though brief, was of great amplitude, and these were classified in a second group as 


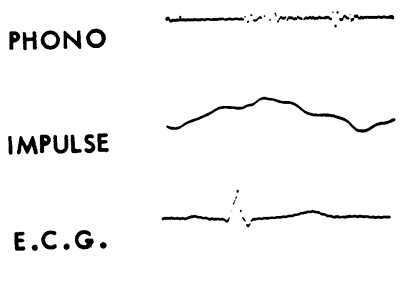

A

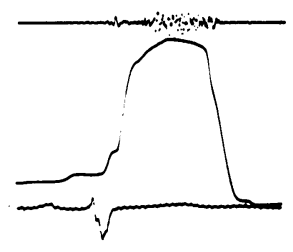

B

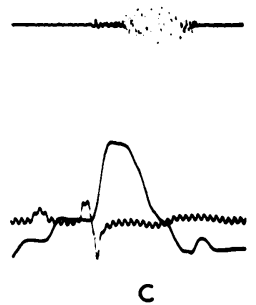

C

Fig. 2.-Types of left parasternal impulse in pulmonary stenosis (D.C. recorder). $A=$ normal type impulse; $\mathrm{B}=$ sustained impulse $\mathbf{C}=$ overacting impulse.

overacting (Fig. 2C), though we recognize that it is impossible to make any hard and fast distinction between these and the normal, the amplitude of movement being certainly influenced by factors such as body build, posture, and emotional state, which are not directly related to the state of the heart. The third group comprised patients whose parasternal impulses were, on the D.C. recorder, distinguished by their longer duration sustained throughout systole (Fig. 2B).

Table I shows the patients divided into these groups according to the form of the parasternal impulse. There were 16 patients with parasternal impulses of normal form. Of these 16, 6 had evidence of mild disease, having right ventricular pressures of $60 \mathrm{~mm}$. $\mathrm{Hg}$ or less, the mildest grade of abnormality on the electrocardiogram, and little or no angiographic evidence of ventricular hypertrophy. The other 10 patients with normal impulses had severe disease indicated by at least two out of the three features studied. Most of this group had ventricular pressures exceeding $100 \mathrm{~mm}$. $\mathrm{Hg}$, and the $x$-ray appearances and electrocardiograms were more positively abnormal.
Twelve patients had sustained impulses of the kind classically associated with pulmonary stenosis. All of them had moderate or severe disease. The right ventricular pressure was more than $100 \mathrm{~mm}$. $\mathrm{Hg}$ in all save two, and every case had angiographic and electrocardiographic evidence of considerable or gross hypertrophy.

Of the two patients with overacting impulses, one had moderate and one very severe disease.

Soft atrial sounds were often heard and recorded by the phonocardiogram at the left sternal edge. Five patients showed atrial beats on the impulse record.

Comparison of A.C. and D.C. Recorders in Pulmonary Stenosis. Having established that the distinction between normal and sustained impulses was of clinical significance, we examined our records to see how the two recorders compared as a means of establishing the form and duration of the cardiac impulse. The normal impulse with its brief duration was recorded equally well by each of them and the tracings obtained from each were frequently identical (Fig. 3A).

TABLE I

PATIENTS WITH PULMONARY STENOSIS CLASSIFIED ACCORDING TO LEFT PARASTERNAL IMPULSE

\begin{tabular}{|c|c|c|c|c|c|c|c|c|c|c|c|}
\hline \multicolumn{4}{|c|}{ Normal } & \multicolumn{4}{|c|}{ Sustained } & \multicolumn{4}{|c|}{ Overacting } \\
\hline $\begin{array}{l}\text { Case } \\
\text { No. }\end{array}$ & $\begin{array}{c}\text { RV } \\
\text { pressure } \\
\text { (mm. Hg) }\end{array}$ & $\begin{array}{c}\text { Angio- } \\
\text { cardiogram } \\
\text { RV+ }\end{array}$ & $\begin{array}{c}\text { Electro- } \\
\text { cardiogram } \\
\text { RV+ }\end{array}$ & $\begin{array}{l}\text { Case } \\
\text { No. }\end{array}$ & $\underset{\text { pressure }}{\text { RV }}$ & $\begin{array}{l}\text { Angio- } \\
\text { cardiogram } \\
\text { RV+ }\end{array}$ & $\begin{array}{c}\text { Electro- } \\
\text { cardiogram } \\
\text { RV+ }\end{array}$ & $\begin{array}{l}\text { Case } \\
\text { No. }\end{array}$ & $\begin{array}{c}\text { RV } \\
\text { pressure } \\
(\mathbf{m m} . \mathbf{H g})\end{array}$ & $\begin{array}{l}\text { Angio- } \\
\text { cardiogram } \\
\text { RV+ }\end{array}$ & $\begin{array}{c}\text { Electro- } \\
\text { cardiogram } \\
\text { RV+ }\end{array}$ \\
\hline $\begin{array}{r}1 \\
2 \\
3 \\
4 \\
5 \\
6 \\
7 \\
8 \\
9 \\
10 \\
11 \\
12 \\
13 \\
14 \\
15 \\
16\end{array}$ & $\begin{array}{r}40 \\
33 \\
30 \\
36 \\
60 \\
35 \\
80 \\
90 \\
100 \\
240 \\
180 \\
140 \\
110 \\
100 \\
80 \\
130\end{array}$ & $\begin{array}{l}Z \\
Z \\
Z \\
\overline{+} \\
- \\
++ \\
++ \\
++ \\
+ \\
+ \\
++ \\
+ \\
+\end{array}$ & $\begin{array}{l}1 \\
1 \\
0 \\
1 \\
1 \\
1 \\
2 \\
1 \\
2 \\
4 \\
4 \\
2 \\
2 \\
3 \\
2 \\
3\end{array}$ & $\begin{array}{l}17 \\
18 \\
19 \\
20 \\
21 \\
22 \\
23 \\
24 \\
25 \\
26 \\
27 \\
28\end{array}$ & $\begin{array}{r}70 \\
90 \\
110 \\
140 \\
160 \\
130 \\
120 \\
150 \\
150 \\
100 \\
120 \\
200\end{array}$ & $\begin{array}{l}++ \\
++ \\
+ \\
+ \\
+ \\
+ \\
+ \\
+ \\
+ \\
+ \\
+ \\
+\end{array}$ & $\begin{array}{l}3 \\
3 \\
3 \\
3 \\
3 \\
3 \\
4 \\
3 \\
4 \\
3 \\
4 \\
3\end{array}$ & $\begin{array}{l}29 \\
30\end{array}$ & $\begin{array}{r}80 \\
200\end{array}$ & $\overline{++}$ & $\begin{array}{l}1 \\
4\end{array}$ \\
\hline
\end{tabular}




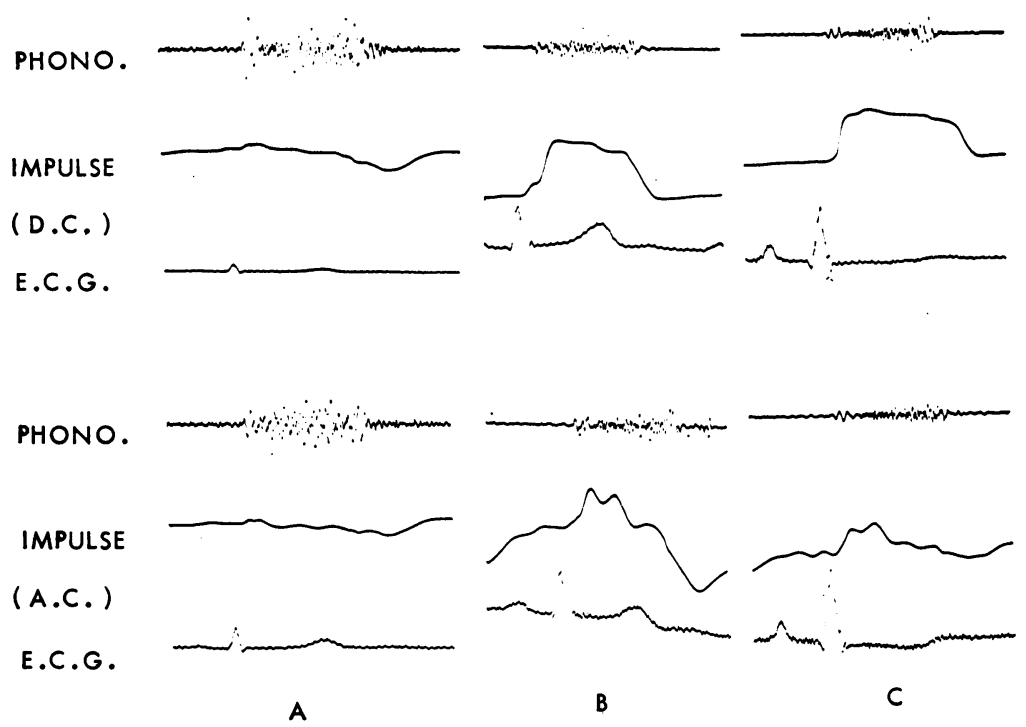

FIG. 3.-Left parasternal impulse recorded by D.C. and A.C. transducers in patients with pulmonary stenosis. $\mathrm{A}=$ normal type impulse; $\mathrm{B}$ and $\mathrm{C}=$ sustained impulses.

The D.C. recorder recorded prolonged impulses faithfully. In no case did it fail to register as sustained an impulse which felt sustained on palpation, while it often demonstrated the prolonged nature of cardiac impulses which were doubtful on clinical examination. The A.C. transducer was much less reliable at recording sustained deflections. Fig. 3B shows a case in which the sustained nature of the impulse is partially represented on the A.C. record while Fig. 3C shows one which looks normal on the A.C. record though the D.C. recorder shows it to be sustained throughout systole. This difference between the recorders is accounted for by the tendency of the A.C. record to return to its baseline during a sustained outward movement and the effect of such distortion is to make the prolonged impulse resemble the normal brief motion of the chest.

In conclusion, the A.C. and D.C. recorders detect equally well the brief outward deflection of a normal parasternal impulse. The sustained impulse which, when present, is a reliable sign of severe pulmonary stenosis, is only detected with certainty by the D.C. instrument though the A.C. device may give an approximate representation of the true movement.

The atrial beats, which were of short duration, were equally well recorded by either instrument.

Left Parasternal Impulse in Atrial Septal Defect. As in pulmonary stenosis, the impulses could be classified as normal (Fig. 4A), overacting
(Fig. 4B), or sustained (Fig. 4D), but a fourth group of patients with impulses that were both overacting and slightly prolonged (Fig. 4C) blurred the distinction between the groups on palpation and, to a lesser extent, on the impulse record. The duration of outward movement in those classified as overacting and long was longer than normal but the record returned to the baseline before the last third of systole.

Table II shows the patients divided according to the nature of their left parasternal impulses, as shown by the D.C. recorder. Six were normal. Eight had the tumultuous overacting impulse of great amplitude and brief duration classically associated with atrial septal defect, and in seven patients the impulse was not only of great amplitude but was also longer than normal. Seven patients had impulses that were fully sustained throughout systole and were indistinguishable from those recorded in cases of severe pulmonary stenosis. Four of these patients with sustained impulses (Cases 25 to 28 ) had pulmonary hypertension at approximately systemic level and might have considerable right ventricular hypertrophy on that account, but the other three had pressures and shunts in no way different from the rest of the patients with atrial septal defects.

None of the patients, in any of the four groups, had angiographic evidence of right ventricular hypertrophy, and their electrocardiograms all 


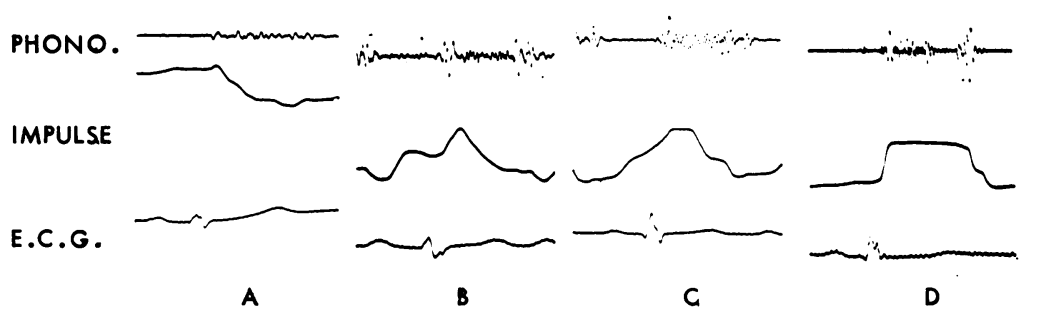

FIG. 4.-Types of left parasternal impulse in atrial septal defect, recorded by D.C. recorder. $A=$ normal type impulse; $B=$ overacting impulse; $C=$ overacting and prolonged impulse; $D=$ sustained impulse.

showed partial right bundle-branch block without further abnormalities suggestive of severe hypertrophy. These aspects are, therefore, omitted from Table I, but besides the right ventricular pressure, we have included a semiquantitative assessment of the size of the left-to-right shunt. A single plus implies a shunt just visible on angiography and with a pulmonary-systemic flow ratio of less than $2 \frac{1}{2}: 1$. A double plus signifies a shunt greater than this. There is some correlation between the presence of an overacting impulse and a big shunt. A small shunt is often found with a normal impulse, when the right ventricular pressure is normal or slightly raised, and with a sustained impulse when pulmonary hypertension is severe.

Atrial beats were recorded in six patients and their presence added to the similarity between some of the impulses and those of pulmonary stenosis.

Comparison of A.C. and D.C. Recorders in Atrial Septal Defect. Those patients with normal or overacting impulses could be investigated equally well with either impulse recorder since the records obtained were virtually identical. The sustained impulses were distorted by the A.C. recorder in a similar fashion to the cases of pulmonary stenosis, in such a way that the record came to resemble a normal one or at least one of the slightly prolonged impulses found in other patients with atrial septal defect. The atrial beats which were found in some patients were equally well recorded by either instrument.

\section{Discussion}

This study has confirmed the findings of others that the left parasternal impulse in pulmonary stenosis may be forceful and sustained throughout systole (Benchimol et al., 1966; Gillam et al., 1964; Schmidt and Craige, 1965; Wood, 1956). Similar sustained impulses have been recorded in pulmonary hypertension due to congenital and rheumatic heart disease, and we believe that it is a sign of right ventricular hypertrophy. The greater number of patients examined in this investigation has enabled us to define more precisely the clinical significance of normal and abnormal impulses. Therefore, in pulmonary stenosis a sustained left parasternal impulse, when present, indicates severe disease, but its absence is of no clinical significance and, in particular, does not necessarily indicate that the condition is mild.

Many of our patients with atrial septal defect had the characteristic overacting impulse associated with this diagnosis, and an impulse of this kind was usually found when the shunt was big. In many the impulse was brief and only the amplitude of movement distinguished it from the normal. Obviously the amplitude depends on factors, such as

TABLE II

PATIENTS WITH ATRIAL SEPTAL DEFECT CLASSIFIED ACCORDING TO LEFT PARASTERNAL IMPULSE

\begin{tabular}{|c|c|c|c|c|c|c|c|c|c|c|c|}
\hline \multicolumn{3}{|c|}{ Normal } & \multicolumn{3}{|c|}{ Overacting } & \multicolumn{3}{|c|}{ Overacting and long } & \multicolumn{3}{|c|}{ Sustained } \\
\hline $\begin{array}{l}\text { Case } \\
\text { No. }\end{array}$ & $\begin{array}{c}\text { RV } \\
\text { pressure } \\
\text { (mm. Hg) }\end{array}$ & Shunt & $\begin{array}{l}\text { Case } \\
\text { No. }\end{array}$ & $\begin{array}{c}\text { RV } \\
\text { pressure } \\
(\mathbf{m m} . \mathbf{H g})\end{array}$ & Shunt & $\begin{array}{l}\text { Case } \\
\text { No. }\end{array}$ & $\begin{array}{c}\text { RV } \\
\text { pressure } \\
(\mathbf{m m} . \mathbf{H g})\end{array}$ & Shunt & $\begin{array}{l}\text { Case } \\
\text { No. }\end{array}$ & 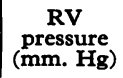 & Shunt \\
\hline $\begin{array}{l}1 \\
2 \\
3 \\
4 \\
5 \\
6\end{array}$ & $\begin{array}{l}40 \\
30 \\
40 \\
60 \\
65 \\
60\end{array}$ & $\begin{array}{c}++ \\
+ \\
++ \\
+ \\
+ \\
+\end{array}$ & $\begin{array}{r}7 \\
8 \\
9 \\
10 \\
11 \\
12 \\
13 \\
14\end{array}$ & $\begin{array}{r}70 \\
40 \\
40 \\
25 \\
35 \\
30 \\
40 \\
35\end{array}$ & $\begin{array}{c}+ \\
++ \\
++ \\
++ \\
++ \\
++ \\
++ \\
+\end{array}$ & $\begin{array}{l}15 \\
16 \\
17 \\
18 \\
19 \\
20 \\
21\end{array}$ & $\begin{array}{l}50 \\
50 \\
40 \\
20 \\
30 \\
20 \\
40\end{array}$ & $\begin{array}{l}++ \\
+ \\
++ \\
++ \\
++ \\
++ \\
++\end{array}$ & $\begin{array}{l}22 \\
23 \\
24 \\
25 \\
26 \\
27 \\
28\end{array}$ & $\begin{array}{r}30 \\
50 \\
40 \\
70 \\
50 \\
120 \\
80\end{array}$ & $\begin{array}{c}++ \\
+ \\
+ \\
+ \\
+ \\
+ \\
+\end{array}$ \\
\hline
\end{tabular}


anxiety and excitement, the cardiac output and body build, which are not necessarily related to the anatomical lesion. For this reason we have not attempted a strict differentiation between the normal and the overacting impulse and no doubt some patients who were classified as having overacting impulses on one occasion might be considered normal on another.

However, several patients were studied more than once and in all cases the cardiac impulses were very similar.

When atrial septal defect was complicated by severe pulmonary hypertension the impulse was always sustained but three patients with nearly normal pulmonary arterial pressure also showed this sign.

Differentiation between the cardiac impulse of pulmonary stenosis and atrial septal defect was made difficult by three factors brought out in this study. First, severe forms of either disease may exist with a left parasternal impulse indistinguishable from normal. Secondly, a sustained impulse is not confined to severe cases of pulmonary stenosis but may be found occasionally in atrial septal defect with only slight pulmonary hypertension. Moreover, many of the overacting impulses found in most cases of atrial septal defect with large shunts are a little more prolonged than normal and may be confused with fully sustained impulses on clinical palpation alone. Finally, the presence of an atrial beat is as common in atrial septal defect as it is in pulmonary stenosis. These difficulties are particularly liable to lead to error in the clinical assessment of the severity of the disease. For instance, pulmonary hypertension was wrongly suspected in some of these cases because of misinterpretation of the nature of the cardiac impulse, and some cases of pulmonary stenosis were mistakenly thought to be mild because of the absence of clinical evidence of right ventricular hypertrophy.

These studies emphasize the importance of the duration of the cardiac impulse in the clinical diagnosis of congenital heart disease. It has been our experience that only a D.C. displacement recorder, or at least an A.C. recorder with a longer time constant than that of the system we used, can reliably detect the sustained nature of an impulse.

Similar distortions of prolonged impulses were reported by Roberts and Jones (1963) who investigated the electronic properties of the crystal microphone used in the "apex cardiogram" which had a time constant of $0.3 \mathrm{sec}$. They pointed out that an A.C. transducer, with a very short time constant responded to velocity of motion rather than displacement and the effect of this was to convert a square wave movement into the kind of biphasic tracing shown in Fig. 1.
Craige and Schmidt (1965) and Schmidt and Craige (1965), in studies of the left parasternal impulse in healthy children and children with pulmonary stenosis, used an A.C. instrument with a time constant of 1.2 seconds which they said gave tracings similar though not identical to those produced by a D.C. machine. However, the comparison records which they reproduced in their paper were of normal non-sustained impulses, and it is therefore impossible to tell for certain if their recorder would always record a sustained impulse faithfully. Theoretical considerations would suggest that it might do so since the time constant is approximately three times the normal length of systole, and hence three times the length of the wave motion to be recorded.

Low frequency distortion can be avoided by the use of a D.C. transducer but practical experience suggests that an A.C. device, if it had a long enough time constant, might be easier to use. This is because of the A.C. instrument's ability to return automatically to its baseline when respiration, which produces much greater swings than the cardiac impulse, is halted for the record to be made. Children, in particular, find much difficulty in holding their breath to order and at a particular phase of respiration.

It is obviously of considerable importance to find out the desirable characteristics of an impulse recorder and further systematic studies are in progress. Meanwhile, reports of work done in this sphere should include details of the apparatus used so that the results of different workers may be compared.

\section{SUMMARY}

Records of the left parasternal impulse have been obtained from 30 patients with pulmonary stenosis and 28 patients with atrial septal defect, using two different kinds of impulse recorder in order to compare both the form of the impulse in the two diseases and the merits of the recording systems.

In pulmonary stenosis a parasternal impulse which is sustained throughout systole is only found in severe disease but a normal brief impulse may occur in mild or severe stenosis.

In atrial septal defect the impulse is usually overacting and brief but sustained impulses are found in patients with severe pulmonary hypertension and in a small number whose pulmonary arterial pressures are only mildly raised. The duration of the overacting impulse is often somewhat longer than that of the normal, and this makes the distinction from the sustained impulse difficult to make on clinical examination alone.

Sustained impulses were faithfully recorded by 
the D.C. recorder but were often distorted by the A.C. recorder in such a way as to make them resemble normal impulses. Normal impulses were equally well recorded by either instrument.

Until some standard specification for impulse recorders has been agreed upon, the characteristics of the instruments used in studies of this kind should be published so that records from different centres may be compared.

We are grateful to the Sheffield Regional Hospital Board for a grant to one of us (R.E.N.) which was used to purchase the D.C. transducer.

\section{REFERENCES}

Beilin, L., and Mounsey, P. (1962). The left ventricular im- pulse in hypertensive heart disease. Brit. Heart f., 24, 409.

Benchimol, A., Wu, T., and Dimond, E. G. (1966). Apex cardiogram in the diagnosis of congenital heart disease. Amer. F. Cardiol., 17, 63.

Craige, E., and Schmidt, R. E. (1965). Precordial movements over the right ventricle in normal children. Circulation, 32, 232.

Gillam, P. M. S., Deliyannis, A. A., and Mounsey, J. P. D. (1964). The left parasternal impulse. Brit. Heart f., 26, 726.

Goodwin, J. F., and Abdin, Z. H. (1959). The cardiogram of congenital and acquired right ventricular hypertrophy. Erit. Heart F., 21, 523.

Roberts, D. V., and Jones, E. S. (1963). A new system for recording the apex beat. Lancet, 1, 1193.

Schmidt, R. E., and Craige E. (1965). Precordial movements over the right ventricle in children with pulmonary stenosis. Circulation, 32, 241.

Wood, P. H. (1956). Diseases of the Heart and Circulation, 2nd ed., p. 58. Eyre and Spottiswoode, London. 